\title{
A cardiac patient training companion
}

\author{
Ines Frederix \\ Medical Doctor student \\ University of Hasselt, Belgium \\ ines.frederix@student.uhasselt.be
}

\begin{abstract}
Emerging biomedical transducers combined with technologies such as radio frequency identification, mobile cellular radio and global positioning systems are about to change the revalidation process of patients that recover from a heart attack or that have excessive fat. This paper explores how, by using these technologies, a training companion can be designed that allows these patients to become nomadic without the stress of a dedicated and costly revalidation environment. An additional advantage of such a solution is that the patient can return earlier to his known home environment.
\end{abstract}

Index Terms - Artificial intelligence, Biomedical transducers, Cardiovascular system, Global Positioning System, Medical services.

\section{INTRODUCTION}

I $\mathrm{N}$ the middle ages, far before there was a belief that body and soul were instrumental for a persons health, often if someone got sick it was explained as the result of an evil mind, ghosts or demons. Besides the fact that this belief let to an isolation of sick people and a possible slowing down in the spreading of some dangerous transferable diseases such as the black dead in the middle ages, no other therapeutically value could be given to this approach. In enlightening ages, doctors started to concentrate on the body trying to understand what was really happening in a sick body. This lead to the fast progress in medicine we have seen over the last 200 years and it stays the key driver for today's progress.

But was it all wrong to link body and soul? The Romans had the saying "healthy in body and soul".[1] Current health care practices that for long time rejected the idea that the soul could influence the health condition of someone have been revising their view profoundly in the last years. Statistics show that two third of causes of death in developed countries have to do with heart diseases, alcohol abuse, excessive fat, ... all factors directly related to the mind setting (or if you like soul) of the affected people. Proper exercising, good nutrition, uncontaminated living environments, are key to reduce the risk of these causes of death.

This manuscript explains in "the relation between exercise and metabolism" the processes that take place in the human body and that can create life threatening conditions. It complements this process description with some statistical evidence and explores the ongoing research to describe the current state of the art on cardiac patient training companion (CPTC).

Based on the current knowledge of the metabolic processes in the human body, the paper formulates a conceptual view of the requirements for a workable CPTC and it invites engineers to start thinking about workable prototypes of such a CPTC using today's available - of the shelf - technologies.

\section{RELATION BETWEEN EXERCISE AND METABOLISM}

\section{A. Theory of energy creation and consumption}

As an introduction, let us have a look at the effects of mildto moderate intensity exercise at a cellular level. By doing this it will become clear why even walking a limited distance can enhance human health. First of all, it is important to know that as human beings we are able to generate energy from numerous sources (e.g. proteins, fat, sugar,...). This energy is necessary to maintain the basal functions of the body (respiration, steady body temperature, heart beating,...). Besides these basal functions, additional energy is required to be able to exercise and to do other physical work. But what are the mechanisms that we use to meet these increased energy demands? And how is this useful in clinical settings?

\section{The function of muscle cells versus fat cells}

We can differentiate muscle cells from fat cells based on their role in metabolism. Muscle cells are primarily involved in energy generation from glucose, amino acids and fatty acids to meet the high energy demands during exercise. Fat cells in contrary have almost solely a storage function (storage of triacylglycerol). [2]

\section{The liver functions as a distribution center}

The liver in the gastro-intestinal system is responsible for the distribution of nutrients to the different tissues of the body. It generates glucose, the universal energy currency of the body during exercise. Although some tissues are able to break down proteins and fat molecules for energy, glucose is the only monomer that can be relied on by all tissue types. And to provide every cell with adequate amounts of glucose, it is important that the concentration of this universal energy currency is maintained at high enough levels in the blood. This is the task of the liver and the regulation is mediated by hormones. During exercise, epinephrine and glucagon 
stimulate the liver to release glucose into the blood. [2] Epinephrine (also called adrenaline) and glucagon are two hormones, released from the adrenal medulla and pancreas respectively, that prevail in the blood in the setting of an exercising person. These hormones travel through the blood to the liver where they stimulate this organ to release glucose by means of glycogenolysis and gluconeogenesis. The former is the cleavage of glycogen (storage form of glucose in the liver) to glucose monomers, which are subsequently released into the blood.(see Fig. 1). The latter is the generation of glucose from other precursors (e.g. breakdown products of fat). [3-6]

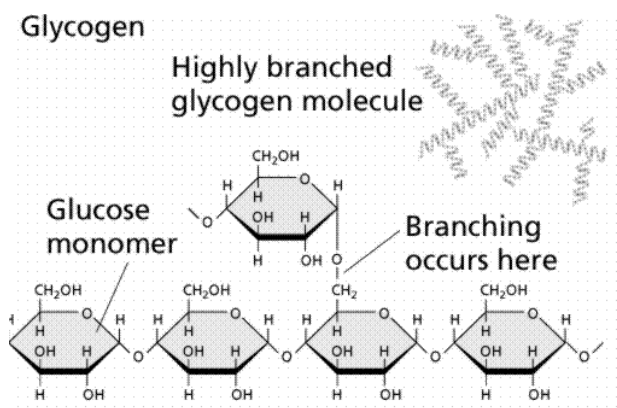

Fig. 1. Glycogen molecule, composed of glucose monomers

The effects of long-term moderate intensity exercise on the type of fuel being used

As can be deduced from Fig. 2, after several hours of mild to moderate exercise, the muscle (and also the liver) glycogen stores become depleted and therefore the liver is no longer capable of generating high amounts of glucose by the process of glycogenolysis. Also notice the gradual increase in the proportion of blood glucose, created by the process of gluconeogenesis from different types of precursors, e.g. glycerol, a breakdown product of fat. Thus we can conclude that when a person is exercising, even at low intensity (e.g. walking, jogging at a slow pace), he or she will be breaking down fat molecules after a certain amount of time. [2]

Changes in the adipocyt during prolonged exercise

What happens in the adipocyt (fat cell) during prolonged exercise? Here, the catecholamines (epinephrine,...) stimulate the adipocyt to release free fatty acids and glycerol, by means of the breakdown of their fat stores. These fatty acids and glycerol then travel through the blood to the liver, where they are converted to glucose (gluconeogenesis). [7]

The processes described are applicable in a clinical setting and prove that a patient, whether in a post-operative situation or not, can benefit tremendously, even from low-intensity exercise (e.g. walking a certain distance each day). Furthermore the theory provides evidence that people who are overweight or obese, do not necessarily need to engage in extreme types of exercise (e.g. running, weight lifting, etc.) to reduce their fat stores.

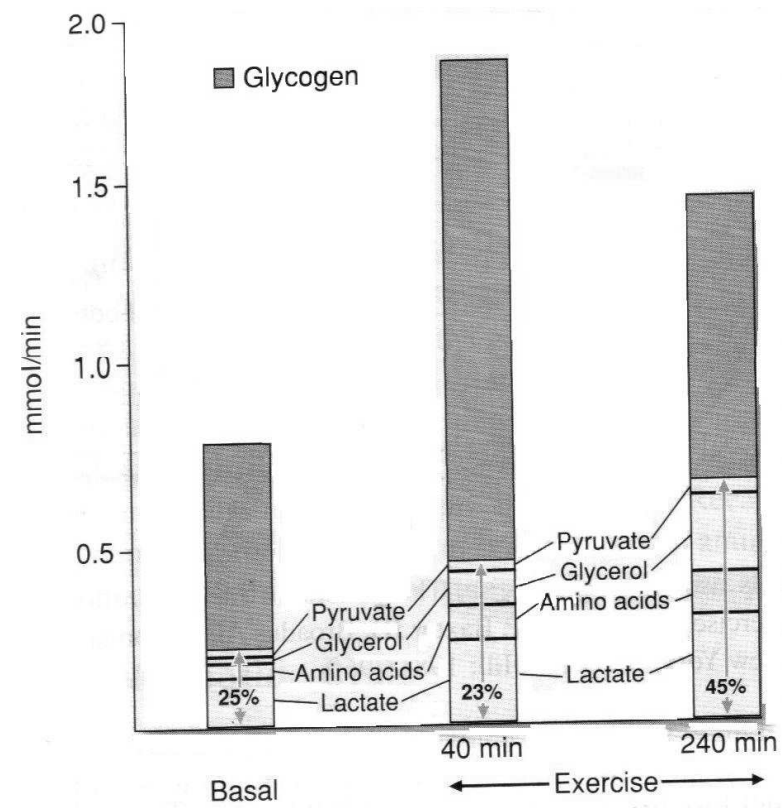

Fig. 2. Proportion of glucose, released from the liver, by glygogenolysis (grey area) and gluconeogenesis (white area) during rest (basal state) or after a certain time of exercise at low intensity

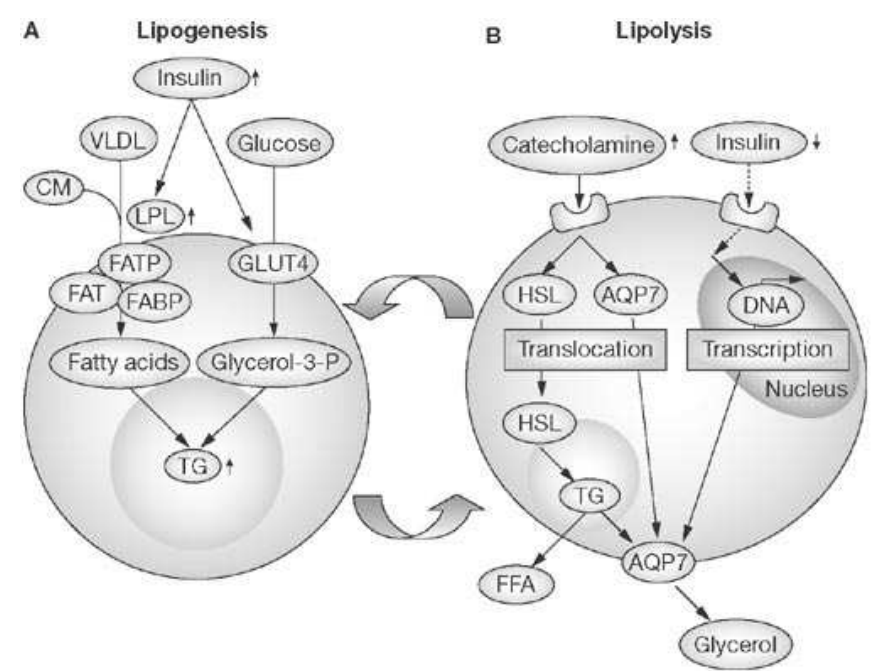

Fig. 3. Catecholamines stimulate the adipocyt to release free fatty acids (FFA) and glycerol, both of which are breakdown products of fat molecules (TG), into the blood.

\section{B. Statistical evidence for the protective effect of exercise on the general health state}

This paragraph documents the effect of long-term exercise using statistical evidence.

\section{Antisenescent and antiapoptotic effect of long-term exercise}

As noted by WERNER Christian et al. long-term exercise induces several cellular changes that result in antisenescent and antiapoptotic cells. When an eukaryotic cell (e.g. cell from a human being) divides, it first needs to copy (replicate) its 
DNA content in order to supply its two daughter cells with identical genetic material. Unfortunately, every time a chromosome (DNA plus histones) is duplicated, some genetic material at the ends is lost due to the inherent replication mechanism of the eukaryotic cell. To prevent this loss of DNA, a reverse transcriptase enzyme called telomerase (TERT) is expressed by the cell. This is essential because when the cell divides multiple times without the protective effect of telomerase, after a certain time, part of the genetic material will be lost, and this will without any doubt result in cell death. So when Werner et al. noticed that the telomerase levels were up-regulated in cardiac cells of mice exercising, compared with sedentary mice, the beneficial effect of 'exercise' became apparent. [8]

\section{Physical activity reduces the relative risk of death}

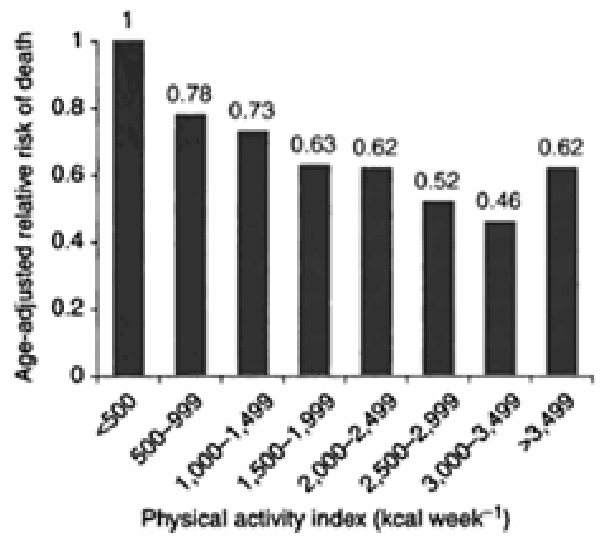

Fig. 4. Age adjusted risk of death

The Harvard Alumni Health Study, conducted early in the twentieth century provided proof that there is an inverse association between the level of physical activity (measured as the number of kilocalories burned in the leisure time of about 16.936 men, enrolled in Harvard college and aged 35-74 years old) and the relative risk of all-cause mortality. These results remained significant following control for smoking, hypertension, etc. confirming the general assumption that inactivity deteriorates human health state. [9]

\section{Conclusions of the American Heart Association}

For a patient that suffered a myocardial infarction in the past, clinical data, gathered by the American Heart Association, indicate that survival and quality of life for this patient can be increased by training on a regular basis. This happens by means of decreased blood pressure, increased HDL cholesterol (good cholesterol) levels and the stabilisation of a healthy weight. [10]

\section{Combined energy restriction and increased physical activity reduce the risk for coronary heart disease \\ One of the basic mechanisms at the origin of atherosclerosis and consequent myocardial infarction is dysfunctional endothelium and deficiencies in the blood clotting cascade. In}

the research results published in the International Journal of Obesity (2001), conclusions about the influence of obesity and related risk factors on the etiology of coronary heart disease could be drawn. The study design measured pre- and poststudy levels of certain principal procoagulation factors (factors that induce blot clotting) and noticed that there was a reduction in the level of these procoagulation factors (e.g. fibrinogen, von Wilebrand factor, etc.) in the obese youth that succeeded in maintaining a certain predefined amount of physical training combined with an energy restricted diet. Again the message that training programmes are beneficial in the prevention of the development of heart diseases is apparent from this paper. [11]

\section{CURRENT CARDIAC TRAINING COMPANIONS}

The theoretical process description and the statistical evidence described in II show that when a person decides to exercise, the duration of the training session is important in that it determines whether glygogen is used to meet the increased energy demands (by means of glycogenolysis), or he/she is actually burning real fat mass. Therefore, a revalidation training companion ( or monitoring system) should not only being capable to inform the person about the total number of kilocalories burned, the distance run and the speed of running, it also needs to make a clear differentiation about the type of fuel (food molecule) being used. Furthermore, it is evident that we need to pay attention to the privacy concerns that such a revalidation training companion could constitute. In addition most of the world population is rapidly ageing: the number of people aged 60 and over as a proportion of the global population will double from $11 \%$ in 2006 to $22 \%$ in 2050 [12]. By then, there will be more old people than children (aged 0-14 years) in the population for the first time in human history. These elderly people are not so experienced with new technologies and sometimes have additional disabilities such as reduced sight and hearing. So the need for an easy to use device with a very good user interface is key for its acceptance.

\section{A. Early devices on the market}

The ICT market is discovering the potential of this market segment. This section, without the ambition to be complete, is introducing, some of these devices on the market and in exploration in the research environment.

\section{1. iPoD - Nike}

Using Radio Frequency Identification technology (RFID), Apple computer and Nike shoes developed an iPoD application that could help not only sportsmen with their training schedule but also patients in a revalidation process. The Nike $+\mathrm{iPoD}$ combination gives runners real-time updates about the speed and length of their workouts via a small RFID device that fits into the soles of Nike shoes, and broadcasts workout data to a small receiver plugged into an iPoD Nano. From a medical point of view, this system is readily applicable 
to help patients during their revalidation, to decrease the percentage of fat mass of obese people or to keep the elderly fit. Due to its simplicity, its implementation in this area seems very realistic to date. [13]

\section{Wii game console}

The recently introduced "wii" game console constitutes an other alternative to assist in attempts to increase physical fitness. The development of the "wii", can be considered a historical milestone in the world of gaming. This easy to use device, is child-friendly and found a mass adoption by the youth. [14]

\section{Woodrow Wilson research on Participatory Sensing}

Within the world of research early steps are also made towards the idea of a training companion. The Woodrow Wilson International Center for Scollars proposes in its recent publication [15] "Participatory Sensing" as a potent health monitoring system. "Participatory Sensing" introduces the concept that the combination of a mobile phone and web technology can enable citizens, and caregivers to monitor themselves, their family members, or patients ... . Imagine the example in which an older person wants to stay at home and live independently, but without his family being worried permanently about his health state that could deteriorate gradually. In this case, The Woodrow Wilson International Center for Scollars proposes the use of participatory sensing to keep the family informed about the social contacts, hours of television watching, miles walked, etc. of the patient. The center completed a feasibility study of this concept in a model family. They published the mainly positive results of this feasibility study in a white paper published in May 2009.[15]

\section{The Information Grand Voyage (IGV) project}

Professor Masaru Kitsuregawa, Director of the Center for Information Fusion at the university of Tokio, and chair of the "The Information Grand Voyage" project steering committee introduced recently this METI $^{1}$ sponsored project at the $\mathrm{OECD}^{2}$ expert conference in Lissbon ${ }^{3}$.

The larger IGV project works on an exploration of the possibilities that become feasible when information of geographical information systems, mobile phone devices of the third generation and sensor information that is easily collectable, such as from accelerometers and motion sensors, can be combined.

The project's proof of the concept "Information as medicine" in the health environment is very promising. A sample of 83 patients received from their advanced mobile phone, also commonly called their personal digital assistant

\footnotetext{
${ }^{1}$ METI : Japanese Ministry of Economy, Trade and Industry

${ }^{2}$ Organisation for Economic Co-operation and Development. The OECD grew out of the OEEC, which was set up in 1948 with support from the United States and Canada to co-ordinate the Marshall Plan for the reconstruction of Europe after World War II

${ }^{3}$ Sensor networks experts conference on 8-9 June 2009, host Portugal
}

(PDA), information related to their health condition. 59 of these patients decided using the received information to improve their workout scheme and to improve their health condition.

Another outcome of the "information as medicine" proof of concept for diabetes patients was that, when their PDA briefed them on their health condition, a statistical significant drop in glycosylated HbA1c levels from $7.5 \%$ to $7.1 \%$ ( a perfect person has an average level of $6 \%$ and a diabetes patient typical has 9 to $8 \%$ depending on the care taken in traditional monitoring methods) was noticed. [16]

\section{THE CONCEPT OF A TRAINING COMPANION}

This paragraph first indicates device specifications, as seen through the glasses of medical staff and then drafts a concept that possibly could inspire engineers to build such a device.

\section{A. A caretaker/users view on the specifications}

With the risk of being too demanding on the characteristics of a CPTC I would suggest to include in the list of desired specifications:

- The companion should be able to determine which type of fuel is burned to provide the energy needed for the physical exercise. This is primordial for obese people, because they benefit more from losing mass as fat than from losing water or glycogen. The duration of the training session will be important in determining whether glygogen is used to meet the increased energy demands (by means of glycogenolysis), or whether the patient is actually burning real fat mass. Water and glycogen provisions will be replenished after a meal, while fat mass buildup happens only when the energy (calories) consumed by the patient exceeds the energy necessary to maintain organ functions.

- Furthermore, for a patient who wants to lose weight, it is important that the CPTC can differentiate between different types of sport. For example, imagine a model man of $70 \mathrm{~kg}$ that exercises for an hour, but that each time chooses another sport. When he walks ( $3 \mathrm{~km} /$ hour), he burns $189 \mathrm{kcal}$; when he jogs $(10 \mathrm{~km} /$ hour$)$ he burns 630 kcal and finally when he walks up and down the stairs, he burns $455 \mathrm{kcal}$. Thus, for a CPTC to be able to help in reducing the risk for a heart disease (e.g. being obese) it should have a mechanism (e.g. GPS system) that can measure whether the patient is ascending/descending a mountain, which way the patient is taking, etc. .

- It is also a fact that the body mass of a patient directly correlates with the number of calories consumed for a given exercise. For example, a person with a total body mass of $70 \mathrm{~kg}$ who walks for 60 minutes at $3 \mathrm{~km} /$ hour will burn $189 \mathrm{kcal}$. When another person of $100 \mathrm{~kg}$ does the same walk, he will burn $270 \mathrm{kcal}$. To conclude, when the CPTC is aware of the weight of the patient it can provide a more accurate estimate of the number of calories burned for a given exercise. 
- $\quad$ Also, for a postoperative revalidation patient, physical exercise is not only a good way to lose body mass, but also a safe way to build up a better condition. In this context two parameters need to be measured continuously: the blood pressure and the heart rate. First of all, a maximal heart rate greater than "220 - the patient age" is dangerous. So, for someone who's 40 years old, the exercise should be terminated when his/her heart rate exceeds 180 beats/hour.

- Specifically for heart patients who suffered a myocardial infarction, ischemia or angina pectoris due to compromised blood supply via the main arteries providing blood, and thereby oxygen and nutrients to the heart, where the heart doesn't function optimally, the blood pressure needs to be monitored. This blood pressure indicates the resistance that the heart needs to overcome to perfuse all the essential organs of the human body. So, when this pressure rises too much during exercise, the heart will fail to perfuse the kidneys, liver, etc. resulting in life-threatening complications.

- The fluid balance is another parameter that the CPTC should be able to monitor consistently. Allow me to illustrate this: imagine a patient with heart decompensation that enters a sauna and that loses consciousness after some time. What happened? The flow of blood produced by the heart is equal to the change in volume divided by the change in time, $\mathrm{F}=\Delta \mathrm{V} / \Delta \mathrm{t}$. When the patient transpires in the sauna, he loses intravascular volume (blood in the blood vessels), which results in inadequate flow to the organs and subsequent organ failure, loss of consciousness, coma and death. The same thing could happen when someone exercises for prolonged time or in a climate that is too warm thereby resulting in extreme transpiration of the patient.

- Safe revalidation should keep in mind the whole profile of the patient. An example: Person 1 suffered a myocardial infarction, not because of being overweight, but because of a cholesterol level that was chronically elevated. Person 2 also suffered a myocardial infarction, but this time due to being obese. For person 1 running and jogging constitute good types of exercise to improve his/her condition. But for person 2, swimming is a healthier alternative. The reason for this difference is because jogging is a weight-bearing sport that could possibly be harmful for the knee joints in obese people. Conclusion: a revalidation training companion should have some knowledge build in and/or a link to a health worker who can follow and assist the patient in the revalidation process.

- Body weight is a dynamic component of our every day lives. It remains constant when the energy consumed (number of calories in the food) equals the energy expended (basal metabolic rate+ physical exercise). When the energy expended exceeds the energy consumed, a energy deficit develops with a resultant decrease in body mass. This formula could be used in practice. When the training companion would contain lists with the number of calories, present in each of the most consumed foods, and it would be able to calculate the energy balance each day, it could inform the patient more accurately on whether he/she will gain or lose weight.

- Finally, a network connection between the CPTC and a database accessible for cardiologists is beneficial in two ways. First of all, the cardiologist can follow-up his patient on a daily basis, which is not yet possible to date (where the cardiologists make an appointment with each patient postoperatively once every few months). Secondly, this network would make long lasting visits no longer necessary thereby reducing the workload for the cardiologist.

\section{B. A concept design of the cardiac training companion}

Table 1 indicates, based on the previous paragraph, the characteristics that a CPTC should have. From this table it is clear that there is a need for a more holistic approach to a revalidation training companion (CPTC). In the prevention of many of the typical civilisation diseases and the revalidation of cardiac patients it can play an invaluable role.

Currently many of the technologies that are needed exist already on a commercial scale. Figure 5 illustrates some of devices that already contain useful technology to support the concept of a CPTC. Some of these devices will have to measure body parameters and movements and can be interconnected using some sort of body network technology such as Bluetooth. Other devices, e.g. the weight scale can be linked through the Wifi home network to the personal digital assistant that also plays an important role as the graphical user interface for the patient and to collect and organise all the necessary data to advice the patient. If the CPTC also serves as guidance for the medical staff that supports the patient then this PDA can submit monitoring data using the gsm network to the health care centre. In option, and less real time, in case the CPTC should also warn emergency services in case sudden changes in the health condition of the patient appear, the home network could collect the data and transmit it to health care centres.

\begin{tabular}{|l|l|l|}
\begin{tabular}{|l} 
Table 1. Cardiac \\
Characteristic
\end{tabular} & Function & Application \\
\hline Fuel type burned & Fat mass or glycogen & $\begin{array}{l}\text { Estimate fat mass loss } \\
\text { more accurately }\end{array}$ \\
\hline Type of sport & $\begin{array}{l}\text { Differentiate speed- } \\
\text { direction-slope }\end{array}$ & $\begin{array}{l}\text { Estimate calories burned } \\
\text { more accurately }\end{array}$ \\
\hline Body mass & $\begin{array}{l}\text { Body mass determines } \\
\text { calories burned }\end{array}$ & $\begin{array}{l}\text { Estimate calories burned } \\
\text { more accurately }\end{array}$ \\
\hline $\begin{array}{l}\text { Blood pressure, } \\
\text { heart rate }\end{array}$ & $\begin{array}{l}\text { Parameters influence } \\
\text { workload of the heart }\end{array}$ & $\begin{array}{l}\text { Ensure safe way to } \\
\text { exercise }\end{array}$ \\
\hline $\begin{array}{l}\text { Fluid balance } \\
\text { registration }\end{array}$ & $\begin{array}{l}\text { Fluid balance influences } \\
\text { organ perfusion }\end{array}$ & $\begin{array}{l}\text { Ensure a safe way to } \\
\text { exercise postoperatively }\end{array}$ \\
\hline Type of sport & $\begin{array}{l}\text { Differentiate between } \\
\text { different sports }\end{array}$ & $\begin{array}{l}\text { Type of sport that is best, } \\
\text { according to body profile }\end{array}$ \\
\hline Energy balance & $\begin{array}{l}\text { Energy balance } \\
\text { preserves body mass }\end{array}$ & $\begin{array}{l}\text { Estimate magnitude of } \\
\text { energy deficit/surplus }\end{array}$ \\
\hline $\begin{array}{l}\text { Network } \\
\text { connection }\end{array}$ & $\begin{array}{l}\text { Online access to data for } \\
\text { the cardiologist }\end{array}$ & $\begin{array}{l}\text { Providing adequate follow- } \\
\text { up of the patient }\end{array}$ \\
\hline
\end{tabular}

Besides these functions the PDA can have a geographical 
positioning system, motion sensor and acceleration meter on board. With these functions commonly found on more and more devices, much data can be collected about the patients their movements and the training done.

In addition, the PDA can include a barcode scanner that, when proper databases will be available on line, will inform the patient about the characteristics of the food and the precautions to take given his health condition, be it cardiac disorders or diabetes.

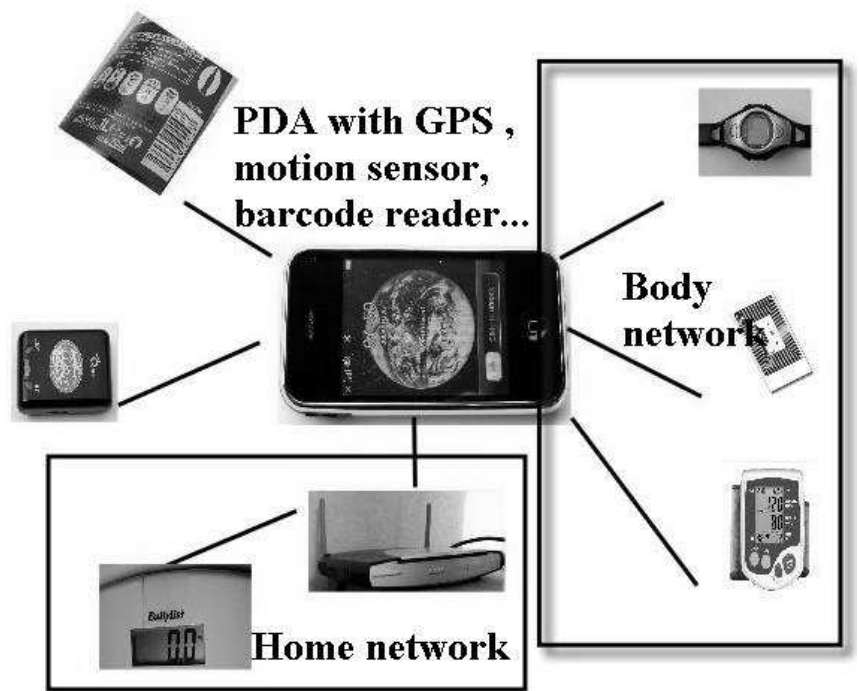

Fig. 5. Networked devices a training companion can build on

\section{CONCLUSION}

There is a clear need for a holistic approach to a revalidation training companion. In the prevention and revalidation of heart diseases and diabetes, typical causes for high death rates in developed countries, the availability of a revalidation training companion is of crucial importance.

But, unfortunately, the idea to use the emerging vast array of emerging technologies ${ }^{4}$ to build such a CPTC has not yet been realised. Current market developments rather address the issue as a secondary specification of another application such as a game console, a PDA. Because of the number of lives that depend on it, the quality of life for many citizens and the costs of health care in a developed society, such a CPTC should deserve a higher priority.

\section{REFERENCES}

[1] Morrison V, Bennett P. An introduction to health psychology. 1st ed. Edinburgh, England: Pearson: Prentice Hall; 2006.

[2] Lieberman M, Marks AD. Basic medical biochemistry: A clinical approach. 3rd ed. Philadelphia: Wolters Kluwer Health; 2009.

[3] Farabee MJ. The digestive system. 2007. URL: http://www.emc.maricopa.edu/faculty/farabee/

\footnotetext{
${ }^{4}$ An Internet of Things networking objects becomes possible using low cost technologies on the market such as RFID, WiFI, Bluetooth, GPS, UMTS,
}

[4] Russell PJ. Igenetics: A molecular approach. 2nd ed. Sansome St., San Francisco: Pearson: Benjamin Cummings; 2006.

[5] Lilly LS. Pathofysiology of heart disease. 4th ed. Philadephia: Wolters Kluwer Health; 2007.

[6] Boron WF, Boulpaep EL. Medical physiology. Updated ed. Philadelphia, Pennsylvania: Elsevier Saunders; 2005.

[7] Nature publishing group. Lipogenesis and lipolysis. 2008. URL: http://img.medscape.com/

[8] Werner C, Hanhoun M, Widmann T, Kazakov A, Semenov A, Pöss J, et al. Effects of physical exercise on myocardial telomere-regulating proteins, survival pathways, and apoptosis [Digital version]. Journal of the American College of Cardiology 2008; 52(6): 470-782. URL: http://cat.inist.fr/

[9] Hardman AE, Stensel DJ. Physical activity and all-cause mortality [Digital version]. Physical activity and health: The evidence explained 2003; 289: 36-50. URL: http://books.google.be/books

[10] American Heart Association. Physical activity. 2009. URL: http://www.americanheart.org/

[11] Berenson GS, Srinivasan SR, Bao W, Newman WP, Tracy RE, Wattigney WA, et al. The changes in haemostatic risk factors for coronary heart disease during a weight reduction program in obese children and adolescents [Digital version]. International journal of obesity 2001; 25(4): 529-532. URL: http://www.nature.com/

[12] E. Mordini, "Social, Ethical and Privacy needs in ICT for older people", EU funded Seniorproject, Center for Science, Society and Citizenship 2008. Available: www.seniorproject.eu

[13] Stay in Sync. Apple computer 2009; URL: http://www.apple.com/ipod/nike/sync.html

[14] Wii MotionPlus, Wii game consoles 2009; URL: http://wii.com

[15] Goldman J, Shilton K, Burke J, Estrin D, Hansen M, Ramanathan N, et al. Participatory sensing, A citizen-powered approach to illuminating the patterns that shape our world [Digital version]. Woodrow Wilson International Center for Scholars 2009; URL: http:// www.wilsoncenter.org/foresight

[16] Kitsuregawa M. Introduction on challenge to harmonize between the use and protection of personal information for mobile and medical service [Digital version]. Information Grand Voyage Project (METI) 2009;

URL: http://www.oecd.org/document/41/0,3343,en_2649_34223_42616233_ 1_1_1_1,00.html 